\title{
Oestrogen receptor alpha Pvull polymorphism and uterine fibroid incidence in Caucasian women
}

\author{
Michał Ciebiera ${ }^{1}$, Małgorzata Wrzosek², Cezary Wojtyła ${ }^{3}$, Tomasz toziński ${ }^{4}$, Grażyna Nowicka², \\ Grzegorz Jakiel'3 ${ }^{3}$ Marek Głowala², Marta Włodarczyk² \\ ${ }^{1} 2^{\text {nd }}$ Department of Obstetrics and Gynaecology, Centre of Postgraduate Medical Education, Warsaw, Poland \\ ${ }^{2}$ Department of Biochemistry and Pharmacogenomics, Faculty of Pharmacy with Division of Laboratory Medicine, \\ Medical University of Warsaw, Warsaw, Poland \\ ${ }^{3} 1^{\text {st }}$ Department of Obstetrics and Gynaecology, Centre of Postgraduate Medical Education, Warsaw, Poland \\ ${ }^{4}$ Department of Obstetrics and Gynaecology, Pro-Familia Hospital, Rzeszów, Poland
}

\begin{abstract}
Introduction: Uterine fibroids (UFs) are benign, monoclonal tumours of the female genital tract that originate from the myometrium. They may be diagnosed in as many as $80 \%$ of women depending on the selected population. UFs depend mostly on steroid hormones. Elevated levels of oestrogens and progesterone are believed to be among the most important factors inducing their formation and growth. These facts suggest that oestrogen (ESR) and progesterone receptors are crucial in UF pathophysiology as well. Previous studies have shown that, in some populations, polymorphisms in ESR genes (e.g. Pvull) constitute an important risk factor for UFs.

Material and methods: The aim of our study was to investigate whether ESR $\alpha$ Pvull polymorphism is associated with an increased risk of UFs in Caucasian women of Polish origin. A total of 197 patients (114 UF-positive and 83 controls) were included in this retrospective cohort study. ESR $\alpha$ gene polymorphism Pvull (rs2234693) was assayed with PCR and restriction fragment length polymorphism (RFLP).

Results: Our study found no significant difference in the occurrence of ESR Pvull polymorphism between women with UFs and UF-free controls in the selected population.

Conclusions: Our results did not indicate a significant association between ESR $\alpha$ gene Pvull polymorphism and the risk of UFs in Caucasian women of Polish origin. More studies and comparisons between races are necessary to clarify the role of ESR $\alpha$ in the development and progression of UFs.
\end{abstract}

Key words: oestrogen, oestrogen receptor, gene polymorphism, genetics, uterine fibroid, leiomyoma.

\section{Introduction}

Uterine fibroids (UFs), benign, monoclonal tumours of the female genital tract, originate from the myometrium [1]. They are diagnosed in a large number of women, and their development depends on various risk factors [2, 3]. These tumours are a major public health problem, due to the symptoms and costs they generate $[4,5]$. The most common UF-dependent symptoms are abnormal, excessive uterine bleeding, pain, infertility, and obstetric pathologies [1, 2, 5, 6]. The enormous healthcare budget burden related to UFs includes the costs of follow-up visits, diagnosis, treatment, and work absenteeism [4, 7].

Numerous reports have been published on the risk factors for UF occurrence [3]. Advanced age, increased body mass index (BMI), positive family history, and genetic predisposition are some of the most important risk factors for UF occurrence [1-3, 8]. According to available high-quality data, fibroid growth depends mostly on steroid hormones [9-12]. Raised levels of oestrogens and progesterone are believed to belong to the most important factors inducing the formation and growth of UFs [9, 12]. However, UF growth was never observed under external administration of steroids only, indicating that pathophysiological pathways of UF and other tumour formation is complex and unknown in many areas [13].

Nowadays, a growing number of data consider progesterone to be a more important factor in initiating myometrial abnormal differentiation and growth than 
oestrogen $[9,12,14]$. Nevertheless, oestrogens still play one of the major roles in the pathophysiology of UFs because they create a strong network of connections with progesterone $[15,16]$. The essential role of oestrogens in the pathophysiology of UFs is confirmed by the fact that UFs rarely occur before menarche and decrease after menopause [15]. Moreover, a significant increase in UF growth rates was observed in the hyperoestrogenic state. Similarly, a higher frequency of UFs was demonstrated in obese women with a high percentage of adipose tissue (strongly associated with hyperoestrogenism) $[10,11,15]$.

Oestrogens influence cellular physiological and pathological pathways through numerous different mechanisms. However, the most important action is binding to specific receptors [17]. Oestrogens interact with oestrogen receptor (ESR) $\alpha$ and ESR $\beta$, which are members of the nuclear receptor family of intracellular receptors [18]. ESR $\alpha$ and ESR $\beta$ are encoded by separate genes, ESR1 and ESR2, respectively, found on different chromosomes [17]. ESRs play important roles in the pathophysiology of various gynaecological diseases, including cancers [19, 20].

ESR $\alpha$ gene, which is believed to play an important role in UF pathology [17], is located on chromosome 6q24-27. It is composed of eight exons, encoding a protein of 595 amino acids with a molecular weight of about $66 \mathrm{KDa}$ [21]. ESR $\alpha$ is present in the uterine muscle as well as in UFs $[10,15]$. Several single nucleotide polymorphisms (SNPs) have been identified in ESR $\alpha$ gene [22]. The majority of research concerning SNPS concentrated on rs2234693 and rs9340799, which are associated with oestrogen dependence, e.g. the onset of natural and surgical menopause [22, 23].

Previous studies by Al-Hendy et al. showed that, in some populations, polymorphisms in catechol-O-methyltransferase and ESR $\alpha$ genes are an important risk factor for UFs $[24,25]$. Moreover, it was found that the two Pvull and Xbal intronic polymorphisms in the ESR1 gene were associated with a significantly increased risk of UFs, especially in black American women [3, 24, 25]. Conversely, Giovindan et al. found a significant association of C allele of ESR1 Pvull polymorphism with both endometriosis and fibroids in Asian Indian women [26].

There are much less available data on ESR $\beta$ and its gene. ESR $\beta$ promoter methylation is suspected to be important in breast cancer pathways [27]. According to Fischer et al., three SNPs (rs2987983, rs3020450, and rs3020449) located in the promoter region of ESR2 gene were not associated with susceptibility to UFs [28]. Similar observations were reported by Zhai et al. for rs 1256049 and rs928554 SNPs of the ESR2 gene [29].

In order to derive a more comprehensive estimation of the associations between ESR $\alpha$ Pvull gene polymor- phisms and UFs risk, we conducted this study in Caucasian women of Polish origin.

The aim of our study was to investigate whether ESR $\alpha$ Pvull polymorphism is associated with an increased risk of UFs in Caucasian women of Polish origin.

\section{Material and methods}

\section{Subjects}

The study was conducted at a gynaecological tertiary centre, between September 2014 and May 2015 in a homogenous group of women of Polish origin. Patients admitted to the gynaecological ward for UFrelated surgery comprised the study group $(n=114)$, while controls were recruited from female patients of the outpatient clinic, who had a negative diagnosis of UFs $(n=83)$. A total of 197 women were included in the study. Before the study procedures all participants signed an informed consent and completed a medical questionnaire. A patient was deemed eligible for the study group if she was diagnosed with at least one UF on ultrasound scans. The control group included subjects with sonographically confirmed fibroid-free uterus. A history of malignancy or an active malignancy was an exclusion criterion for both groups. The Local Ethics Committee approved the study protocol.

\section{Anthropometry}

Based on anthropometric measurements the BMI index was calculated [30]. Obesity was classified according to the World Health Organisation criteria [31], i.e. subjects with $\mathrm{BMI} \geq 30 \mathrm{~kg} / \mathrm{m}^{2}$ were considered obese.

\section{Genotyping}

The ESRa gene (T/C) Pvull polymorphism (rs2234693) was assayed with the method of PCR and restriction fragment length polymorphism (RFLP). Two millilitres of blood were collected in an EDTA vacutainer from the patients as well as the controls. Genomic DNA was extracted from peripheral blood leukocytes of all study subjects using Extractme DNA blood kit (Blirt S.A. Gdańsk, Poland), according to the manufacturer's instructions. DNA concentrations and quality were measured using Quawell Q5000 UV-vis spectrophotometer (Quawell, San Jose, CA, USA). The ESR $\alpha$ rs2234693 polymorphisms were determined according to a previous report (Lorentzon, 1999). Approximately 50 ng of genomic DNA was amplified in a $25-\mu \mathrm{l}$ reaction mixture consisting of $0.4 \mu \mathrm{M}$ forward primer (5' CTGCCACCCTATCTGTATCTTTTCCTATTCTCC-3'), $0.4 \mu \mathrm{M}$ reverse primer (5' TCTTTCTCTGCCACCCTGGCGTCGATTATCTGA-3'), $0.4 \mathrm{mM}$ of each of dNTPs, $2.5 \mathrm{mM} \mathrm{Mg+}$, 1x PCR buffer, and $5 \cup$ Taq polymerase (New England 
Biolabs, Inc., Beverly, MA, USA). PCR was carried out in 30 cycles at $95^{\circ} \mathrm{C}$ for $30 \mathrm{sec}, 68^{\circ} \mathrm{C}$ for $30 \mathrm{sec}$, and $72^{\circ} \mathrm{C}$ for $60 \mathrm{sec}$ (2720 Thermocycler, Applied Biosystems). The $1.3-\mathrm{kb}$ product was cleaved with $5 \mathrm{U}$ of $P$ vull restriction endonuclease (New England Biolabs, Inc., Beverly, MA, USA), electrophoresed, and analysed on $2.5 \%$ agarose gel. Genotypes for ESR $\alpha$ polymorphisms were termed TT, TC, and CC.

\section{Statistical analysis}

All statistical calculations were performed with Statistica software (version 12.0). Continuous variables were expressed as mean \pm standard deviation (SD). Normality of distribution was evaluated using ShapiroWilk test. Continuous variables were compared with the Mann-Whitney U-test. Hardy-Weinberg equilibriums were tested to compare the observed and expected genotype frequencies. Genetic variants were expressed as ( $N$, frequency) and were compared using Chi square tests. The relationship between UF incidence and ESR $\alpha$ genotypes was further evaluated using logistic regression models, where UFs were entered as outcome variable, and the predictors were BMI, family history of UFs, and genotypes of the ESR $\alpha$ gene. The odds ratio (95\% confidence interval) was calculated before and after the adjustment for age, $p<0.05$ was considered significant.

\section{Results}

A total of 197 Caucasian unrelated women (114 UF-positive, 83 UF-negative) were studied: median age 41 years, median BMI $24.9 \mathrm{~kg} / \mathrm{m}^{2}$. The age did not differ significantly between the UF-positive and control group (Table 1). UF-positive women had a higher BMI than women with no symptoms of UF $(p<0.002)$, and they were more likely to be obese (BMI $\geq 30 \mathrm{~kg} / \mathrm{m}^{2}$ was found in $21.93 \%$ of UF-positive subjects vs. $7.23 \%$ in the controls).

The ESR $\alpha$ (T/C) Pvull genotype frequencies were within the Hardy-Weinberg Equilibrium $\left(\chi^{2}=0.89\right.$, $p=0.345)$. The frequency of minor allele (T allele) was 0.43 in all studied subjects, and 0.42 and 0.44 among UF patients and controls, respectively. The genotype distribution and the allele frequencies among the controls and UF patients are shown in Table 2. There were no significant differences in genotype and allele frequencies of studied ESR gene polymorphisms between the cases and controls.

In logistic regression analyses, no significant association was found between the presence of the $T$ allele of the ESR $\alpha$ gene Pvull polymorphism and the presence or absence of UFs, both in the unadjusted and ageadjusted analyses (Table 3 ). The family history of UFs $(\mathrm{OR}=3.39,95 \% \mathrm{Cl}: 1.67-6.86 ; p=0.001)$ and obesity
Table 1. Characteristics of study subjects

\begin{tabular}{lccl}
\hline & $\begin{array}{c}\text { UF } \\
(n=114)\end{array}$ & $\begin{array}{c}\text { Controls } \\
(n=83)\end{array}$ & $p$-value \\
\hline Age (years) & $42 \pm 8$ & $42 \pm 11$ & 0.958 \\
\hline Weight $(\mathrm{kg})$ & $72.10 \pm 13.06$ & $66.64 \pm 11.72$ & 0.003 \\
\hline Height $(\mathrm{m})$ & $166.28 \pm 5.64$ & $166.75 \pm 5.44$ & 0.448 \\
\hline BMI $\left(\mathrm{kg} / \mathrm{m}^{2}\right)$ & $26.09 \pm 4.62$ & $24.03 \pm 4.47$ & 0.002 \\
\hline $\begin{array}{l}\text { Values are presented as means } \pm \text { standard deviation. Differences between } \\
\text { patients with uterine fibroids and the control group were tested using } \\
\text { Mann-Whitney U-test. UF - uterine fibroids; BMI - body mass index }\end{array}$
\end{tabular}

Table 2. Distribution of genotype and allele frequencies of the $\mathrm{ESR} \alpha-397 \mathrm{~T} / \mathrm{C}$ gene polymorphism in uterine fibroid patients and the control group.

\begin{tabular}{lccc}
$\begin{array}{lccc}\text { ESR } \alpha \text { gene } \\
\text { polymorphisms }\end{array}$ & $\begin{array}{c}\text { UF } \\
(n=114)\end{array}$ & $\begin{array}{c}\text { Controls } \\
(n=83)(\%)\end{array}$ & $\begin{array}{c}\chi^{2} \text { and } \\
p \text {-value }\end{array}$ \\
\cline { 1 - 3 } TT, $n(\%)$ & $18(15.8)$ & $15(18.1)$ & $\begin{array}{c}\chi^{2}=0.19 \\
p=0.9099\end{array}$ \\
\cline { 1 - 3 } TC, $n(\%)$ & $60(52.6)$ & $43(51.8)$ & \\
\cline { 1 - 3 } CC, $n(\%)$ & $36(31.6)$ & $25(30.1)$ & \\
\cline { 1 - 3 } T allele & $96(42)$ & $73(44)$ & $\begin{array}{c}\chi^{2}=0.14 \\
p=0.708\end{array}$ \\
\cline { 1 - 3 } C allele & $132(58)$ & $93(56)$ & \\
\hline
\end{tabular}

$\chi^{2}$ test was performed to assess the differences in genotype frequency between the patients and healthy controls. UF - uterine fibroids; ESR - oestrogen receptor

Table 3. Odds ratio for uterine fibroids and history of fibroids and $\mathrm{BMI} \geq 30 \mathrm{~kg} / \mathrm{m}^{2}$ among studied subjects

\begin{tabular}{|c|c|c|}
\hline & OR $(95 \% \mathrm{Cl})$ & $p$-value \\
\hline \multicolumn{3}{|c|}{ Crude logistic regression model } \\
\hline Family history of fibroids & $3.39(1.67-6.86)$ & 0.001 \\
\hline $\mathrm{BMI} \geq 30 \mathrm{~kg} / \mathrm{m}^{2}$ & $3.60(1.40-9.30)$ & 0.008 \\
\hline $\begin{array}{l}\text { ESR } \alpha \text { gene polymorphisms } \\
\text { (presence of T allele) }\end{array}$ & $0.93(0.50-1.73)$ & 0.827 \\
\hline \multicolumn{3}{|c|}{ Age-adjusted logistic regression model } \\
\hline Family history of fibroids & $3.50(1.70-7.20)$ & 0.001 \\
\hline $\mathrm{BMI} \geq 30 \mathrm{~kg} / \mathrm{m}^{2}$ & $4.01(1.51-10.68)$ & 0.005 \\
\hline $\begin{array}{l}\text { ESR } \alpha \text { gene polymorphisms } \\
\text { (presence of T allele) }\end{array}$ & $0.95(0.49-1.83)$ & 0.871 \\
\hline
\end{tabular}

$\mathrm{OR}$ - odds ratio; $\mathrm{Cl}$ - confidence interval; $\mathrm{BMI}$ - body mass index; ESR - oestrogen receptor

$(\mathrm{OR}=3.60,95 \% \mathrm{Cl}: 1.40-9.30 ; p=0.008)$ were found to be risk factors for UFs in our study group.

\section{Discussion}

As stated by Govindan et al., differential origin and physiological heterogeneity generates interest to understand the role of hormone receptors in UFs [26]. The analysis of different SNPs may be seen as wide genomic screening for genes that may be involved in the development of multifactorial diseases, such as UFs [32]. Despite existing reports regarding an increased risk of UFs in both black and Asian Indian women car- 
rying rs2234693 polymorphism of ESR1 gene [24, 26], our team did not find such an association in Caucasian women of Polish origin. Our data are consistent with the data of researchers from Germany [33] and Italy [34]. However, the advantage of our study results from a strongly homogenous group of women from Poland (living in the Lubelskie and Mazowieckie provinces), in comparison with other studies, e.g. the study by Denschlag et al. in which the controls were males [33].

Available data indicate that UFs may be found more commonly and they are more numerous and larger in African-American women compared to women of other origins $[35,36]$. African-American women are the majority among women undergoing hysterectomy for UFs $[35,37]$, and the incidence of UFs in this group is about three to five times higher than in Caucasians $[3,36]$. This difference may be, at least partially, explained by higher concentrations of steroid hormones (oestrogens) in African-American women than in Caucasian women, and higher incidence of obesity - increased body weight affects the oestrogen metabolism [2, 5, 35].

Al-Hendy et al. [24] and Govindan et al. [26] suggested that the high incidence of UFs in African-American women may be explained by a high frequency of specific ESRa gene polymorphisms. Kitawaki et al. found that SNP rs2234693 PP genotype was less common in women with endometriosis, adenomyosis, and UFs [38]. These authors also observed a high frequency of the $T$ allele in patients with UFs (approx. 60.0\% vs. $33 \%$ in patients without this disease) [38]. Hsieh et al. reported that rs2234693 C allele and related genotypes were associated with an enhanced risk of endometriosis and UF [39].

Numerous studies support the role of ESR $\alpha$ gene polymorphisms in physiological and pathological processes in women. Homozygosity of selected alleles of the ESR $\alpha$ gene was found to be associated with the earlier onset (by about one year) of menopause [23]. Some authors suggested that the PP genotype of rs2234693 polymorphism is 'a relatively oestrogen-insensitive genotype' and that women with the $p$ allele may gain more benefit from hormonal replacement therapy regarding fracture risk [17, 40, 41]. According to the study by Andersen et al. some ESR polymorphisms are significantly associated with increased breast cancer risk, as well as risk for other diseases in which oestrogens are implicated [42]. A study by Weiderpass et al. suggested that $\mathrm{ESR} \alpha$ polymorphisms might protect against endometrial cancer [19].

Therefore, it should be considered why ESR $\alpha$ gene polymorphisms might modify the risk of UFs. One of the possible mechanisms may be attributed to rs2234693 polymorphism, which affects ESR $\alpha$ gene transcription and expression [43]. The position of rs2234693 in an intron near the gene promoter (these parts often contain a larger number of regulatory sequences) might sug- gest a possible role in either transcription regulation or mRNA processing and stability [17]. Similar observations were published by Beleza-Maireles et al., who concluded that ESR $\alpha$ rs2234693 polymorphism may influence receptor function because of the differential splicing of the mRNA transcript [44]. Herrington et al. reported that some rs2234693 polymorphisms eliminate a functional binding site for transcription factors, which might result in much lower ESR $\alpha$ transcription [43]. Concluding, the selected ESR $\alpha$ polymorphism may significantly affect protein synthesis and function [45]. However, available data of the effect of this polymorphism on receptor activity influence are still unclear [46].

Shaik et al. observed a significant increase in ESR $\alpha$ and mitochondrial cytochrome $b$ transcript levels in UFs [47] and suggested that elevated ESR $\alpha$ levels contribute an advantage to oestrogen in mediating signal transduction through mitochondrial ER $\alpha(m t E R \alpha)$. Therefore, it seems that an increased expression of ESR $\alpha$ might be associated with enhanced mitochondrial gene transcription and may result in elevated mitochondrial cytochrome $b$ level in UF tumours, which might have a direct effect on the mitochondrial respiratory chain activity [47].

The occurrence of UFs is a multifactorial process [5, 48], and in some populations certain ESR $\alpha$ gene variants may belong to major factors affecting UF occurrence or symptom severity, while in other populations the same genetic polymorphisms may not be of clinical significance. Therefore, we suggest that ESR $\alpha$ receptor polymorphisms modify the risk of UFs in African-American and Asian women, but not in Caucasian women [24, $26,38,39]$. This suggestion is supported by our present study (Polish women) and data presented by Denschlag et al. (German women) [33] and by Massart et al. (Italian women) [34] as well as in the meta-analysis performed by Feng et al. [49].

It should be underlined that obesity appears to be an important risk factor for UFs [3, 8]. In addition, enhanced oestrogen levels observed in UF-positive patients with an increased BMI strengthens the role of oestrogen in UF pathophysiology [50]. However, the effect of an interaction between obesity and ESR $\alpha$ gene polymorphisms is not clear. In our previous studies, being overweight and obese statistically correlated with UF occurrence [8]. However, this still did not explain the selected ESR $\alpha$ polymorphism incidence and the higher risk of UFs.

The observed differences in UF risk may be related to the occurrence of other currently not clearly identified specific genetic variants. The effect of rs934099 in ESR $\alpha$ gene [24] as well as [51] rs3808351 polymorphism in the gene coding G-protein-coupled oestrogen receptor (GPR30), a member of the G-protein-coupled receptor 1 family, was recently proven to be associated 
with UF risk occurrence and a number of tumours [51]. However, more data are necessary to assess the role of these genetic variants in UF development. A study by Veronica et al. demonstrated that genetic variants of progesterone receptor may play an important role in the pathogenesis of UFs. In this study, an increased expression of progesterone receptor $\beta$ isoform was suggested to be responsible for the activation of ESRs and increased oestrogen production [50]. Perhaps this relationship concerns more selected ESR $\alpha$ polymorphisms, which could justify an increased risk of UFs.

An enhanced expression of the ESR gene is observed in UF as compared to normal uterine smooth muscle [10]. Furthermore, UF cells express an enhanced sensitivity to oestrogens compared to normal smooth muscles [15]. Taking the menstrual cycle into consideration, increased UF growth is observed in the luteal phase, indicating an effect of progesterone [9, 14]. In vitro studies showed that the proliferative potential of tumour tissue is stimulated by oestrogens, which also lower the apoptosis of tumour cells [52, 53]. UF itself produces a certain amount of oestrogens using circulating androgens. Aromatase present in pathological myocytes transforms androgens into oestrogens, which stimulate the growth of UFs [54]. These mechanisms may be related to selected ESR $\alpha$ polymorphisms. Therefore, further studies on the role of ESR $\alpha$ gene variants in UF development are necessary. Another issue is the impact of SNPS on the effectiveness of UF treatment. The effect of drugs affecting pathways dependent on oestrogen and progesterone may be modified by the receptor gene variants, and it should be a subject of research [15].

\section{Conclusions}

Our results did not indicate a significant association between the ESR $\alpha$ gene Pvull polymorphism and the risk of UFs in Caucasian women of Polish origin. More studies are necessary to clarify the role of ESR $\alpha$ in the development and progression of UFs and the effect of $E S R \alpha$ genetic variants on the effectiveness of UF therapy. It might be helpful to develop individually tailored therapies with optimal patient matching and selection of treatment.

\section{Disclosure}

The authors report no conflict of interest.

\section{References}

1. Stewart EA, Laughlin-Tommaso SK, Catherino WH, et al. Uterine fibroids. Nat Rev Dis Primers 2016; 2: 16043.

2. Parker WH. Etiology, symptomatology, and diagnosis of uterine myomas. Fertil Steril 2007; 87: 725-36.
3. Stewart EA, Cookson CL, Gandolfo RA, Schulze-Rath R. Epidemiology of uterine fibroids: a systematic review. BJOG 2017; 124: 1501-1512.

4. Soliman AM, Yang H, Du EX, et al. The direct and indirect costs of uterine fibroid tumors: a systematic review of the literature between 2000 and 2013. Am J Obstet Gynecol 2015; 213: 141-160.

5. Al-Hendy A, Myers ER, Stewart E. Uterine Fibroids: Burden and Unmet Medical Need. Semin Reprod Med 2017; 35: 473-480.

6. Ras R, Ksiazek M, Barnas E, et al. Benign metastasizing leiomyoma in triple location: lungs, parametria and appendix. Menopause Rev 2016; 15: 117-121.

7. Stepniak A, Czuczwar P. 3D Power Doppler vascular indices as a novel technique in assessing the outcome of minimally invasive techniques in uterine fibroids treatment. Menopause Rev 2017; 16: 118-121.

8. Ciebiera M, Wlodarczyk M, Slabuszewska-Jozwiak A, et al. Influence of vitamin $D$ and transforming growth factor beta3 serum concentrations, obesity, and family history on the risk for uterine fibroids. Fertil Steril 2016; 106: 1787-1792.

9. Ishikawa H, Ishi K, Serna VA, et al. Progesterone is essential for maintenance and growth of uterine leiomyoma. Endocrinology 2010; 151: 2433-2442.

10. Maruo T, Ohara N, Wang J, Matsuo H. Sex steroidal regulation of uterine leiomyoma growth and apoptosis. Hum Reprod Update 2004; 10: 207-220.

11. Borahay MA, Al-Hendy A, Kilic GS, Boehning D. Signaling Pathways in Leiomyoma: Understanding Pathobiology and Implications for Therapy. Mol Med 2015; 21: 242-256.

12. Bulun SE. Uterine fibroids. N Engl J Med 2013; 369: 1344-1355.

13. Surman M, Janik ME. Stress and its molecular consequences in cancer progression. Postepy Hig Med Dosw (Online) 2017; 71: 485-499.

14. Chill HH, Safrai M, Reuveni Salzman A, Shushan A. The Rising PhoenixProgesterone as the Main Target of the Medical Therapy for Leiomyoma. Biomed Res Int 2017; 2017: 4705164.

15. Borahay MA, Asoglu MR, Mas A, et al. Estrogen Receptors and Signaling in Fibroids: Role in Pathobiology and Therapeutic Implications. Reprod Sci 2017; 24: 1235-1244.

16. Moravek MB, Bulun SE. Endocrinology of uterine fibroids: steroid hormones, stem cells, and genetic contribution. Curr Opin Obstet Gynecol 2015; 27: 276-283.

17. Jakimiuk A, Nowicka M, Bogusiewicz M, et al. Prevalence of estrogen receptor alpha Pvull and Xbal polymorphism in population of Polish postmenopausal women. Folia Histochem Cytobiol 2007; 45: 331-338.

18. Dahlman-Wright K, Cavailles V, Fuqua SA, et al. International Union of Pharmacology. LXIV. Estrogen receptors. Pharmacol Rev 2006; 58: 773-781.

19. Weiderpass E, Persson I, Melhus H, et al. Estrogen receptor alpha gene polymorphisms and endometrial cancer risk. Carcinogenesis 2000; 21 : 623-627.

20. Mendez-Lopez LF, Zavala-Pompa A, Cortes-Gutierrez El, et al. Leptin receptor expression during the progression of endometrial carcinoma is correlated with estrogen and progesterone receptors. Arch Med Sci 2017; 13: 228-235.

21. Ponglikitmongkol M, Green S, Chambon P. Genomic organization of the human oestrogen receptor gene. EMBO J 1988; 7: 3385-3388.

22. Araújo KL, de Rezende LCD, Souza LS, et al. Prevalence of estrogen receptor alpha Pvull (c454-397T > C) and Xbal (c454A > G) polymorphisms in a population of Brazilian women. Braz Arch Biol Technol 2011; 54: 1151-1157.

23. Weel AE, Uitterlinden AG, Westendorp IC, et al. Estrogen receptor polymorphism predicts the onset of natural and surgical menopause. J Clin Endocrinol Metab 1999; 84: 3146-3150.

24. Al-Hendy A, Salama SA. Ethnic distribution of estrogen receptor-alpha polymorphism is associated with a higher prevalence of uterine leiomyomas in black Americans. Fertil Steril 2006; 86: 686-693.

25. Al-Hendy A, Salama SA. Catechol-O-methyltransferase polymorphism is associated with increased uterine leiomyoma risk in different ethnic groups. J Soc Gynecol Investig 2006; 13: 136-144.

26. Govindan S, Shaik NA, Vedicherla B, et al. Estrogen receptor-alpha gene (T/C) Pvu II polymorphism in endometriosis and uterine fibroids. Dis Markers 2009; 26: 149-154

27. Gao L, Qi X, Hu K, et al. Estrogen receptor beta promoter methylation: a potential indicator of malignant changes in breast cancer. Arch Med Sci 2016; 12: 129-136. 
28. Fischer C, Juhasz-Boess I, Lattrich C, et al. Estrogen receptor beta gene polymorphisms and susceptibility to uterine fibroids. Gynecol Endocrinol 2010; 26: 4-9.

29. Zhai XD, Ye Y, Yang Y, et al. No association between estrogen receptor beta polymorphisms and uterine leiomyoma. DNA Cell Biol 2009; 28: 633-636.

30. Jablonowska-Lietz B, Wrzosek M, Wlodarczyk M, Nowicka G. New indexes of body fat distribution, visceral adiposity index, body adiposity index, waist-to-height ratio, and metabolic disturbances in the obese. Kardiol Pol 2017; 75: 1185-1191.

31. WHO. Obesity: preventing and managing the global epidemic. Report of a WHO consultation. World Health Organ Tech Rep Ser 2000; 894: i-xii, 1-253.

32. El-Shennawy GA, Elbialy AA, Isamil AE, El Behery MM. Is genetic polymorphism of ER-alpha, CYP1A1, and CYP1B1 a risk factor for uterine leiomyoma? Arch Gynecol Obstet 2011; 283: 1313-1318.

33. Denschlag D, Bentz EK, Hefler L, et al. Genotype distribution of estrogen receptor-alpha, catechol-O-methyltransferase, and cytochrome P450 17 gene polymorphisms in Caucasian women with uterine leiomyomas. Fertil Steril 2006; 85: 462-467.

34. Massart F, Becherini L, Gennari L, et al. Genotype distribution of estrogen receptor-alpha gene polymorphisms in Italian women with surgical uterine leiomyomas. Fertil Steril 2001; 75: 567-570.

35. Stewart EA, Nicholson WK, Bradley L, Borah BJ. The burden of uterine fibroids for African-American women: results of a national survey. J Womens Health (Larchmt) 2013; 22: 807-816.

36. Eltoukhi HM, Modi MN, Weston M, et al. The health disparities of uterine fibroid tumors for African American women: a public health issue. Am J Obstet Gynecol 2014; 210: 194-199.

37. Marshall LM, Spiegelman D, Barbieri RL, et al. Variation in the incidence of uterine leiomyoma among premenopausal women by age and race. Obstet Gynecol 1997; 90: 967-973.

38. Kitawaki J, Obayashi $\mathrm{H}$, Ishihara $\mathrm{H}$, et al. Oestrogen receptor-alpha gene polymorphism is associated with endometriosis, adenomyosis and leiomyomata. Hum Reprod 2001; 16: 51-55.

39. Hsieh YY, Wang YK, Chang CC, Lin CS. Estrogen receptor alpha-351 $\mathrm{Xbal}{ }^{*} \mathrm{G}$ and $-397 \mathrm{Pvull}^{*} \mathrm{C}$-related genotypes and alleles are associated with higher susceptibilities of endometriosis and leiomyoma. Mol Hum Reprod 2007; 13: 117-122.

40. Salmen T, Heikkinen AM, Mahonen A, et al. The protective effect of hormone-replacement therapy on fracture risk is modulated by estrogen receptor alpha genotype in early postmenopausal women. J Bone Miner Res 2000; 15: 2479-2486.

41. Koivu TA, Fan YM, Mattila KM, et al. The effect of hormone replacement therapy on atherosclerotic severity in relation to ESR1 genotype in postmenopausal women. Maturitas 2003; 44: 29-38.

42. Andersen TI, Heimdal KR, Skrede M, et al. Oestrogen receptor (ESR) polymorphisms and breast cancer susceptibility. Hum Genet 1994; 94: 665-670.

43. Herrington DM, Howard TD, Brosnihan KB, et al. Common estrogen receptor polymorphism augments effects of hormone replacement therapy on E-selectin but not C-reactive protein. Circulation 2002; 105 : 1879-1882.

44. Beleza-Meireles A, Omrani D, Kockum I, et al. Polymorphisms of estrogen receptor beta gene are associated with hypospadias. J Endocrinol Invest 2006; 29: 5-10.

45. Maynadier M, Nirde P, Ramirez JM, et al. Role of estrogens and their receptors in adhesion and invasiveness of breast cancer cells. Adv Exp Med Biol 2008; 617: 485-491.

46. Gennari L, Merlotti D, De Paola V, et al. Estrogen receptor gene polymorphisms and the genetics of osteoporosis: a HuGE review. Am J Epidemiol 2005; 161: 307-320.

47. Shaik NA, Lone WG, Khan IA, et al. Enhanced transcription of estrogen receptor alpha and mitochondrial cytochrome $b$ genes in uterine leiomyomas. Gynecol Endocrinol 2011; 27: 1094-1098.

48. Ciebiera M, Wlodarczyk M, Wrzosek $M$, et al. Role of Transforming Growth Factor beta in Uterine Fibroid Biology. Int J Mol Sci 2017; 18: pii: E2435.

49. Feng $Y$, Lin $X$, Zhou $S$, et al. The associations between the polymorphisms of the ER-alpha gene and the risk of uterine leiomyoma (ULM). Tumour Biol 2013; 34: 3077-3082.
50. Veronica M, Ali A, Venkateshwari A, et al. Association of estrogen and progesterone receptor gene polymorphisms and their respective hormones in uterine leiomyomas. Tumour Biol 2016; 37: 8067-8074.

51. Kasap B, Ozturk Turhan N, Edgunlu T, et al. G-protein-coupled estrogen receptor-30 gene polymorphisms are associated with uterine leiomyoma risk. Bosn J Basic Med Sci 2016; 16: 39-45.

52. Barbarisi A, Petillo O, Di Lieto A, et al. 17-beta estradiol elicits an autocrine leiomyoma cell proliferation: evidence for a stimulation of protein kinase-dependent pathway. J Cell Physiol 2001; 186: 414-424.

53. Chen HW, Liu JC, Chen JJ, et al. Combined differential gene expression profile and pathway enrichment analyses to elucidate the molecular mechanisms of uterine leiomyoma after gonadotropin-releasing hormone treatment. Fertil Steril 2008; 90: 1219-1225.

54. Sumitani H, Shozu M, Segawa T, et al. In situ estrogen synthesized by aromatase $\mathrm{P} 450$ in uterine leiomyoma cells promotes cell growth probably via an autocrine/intracrine mechanism. Endocrinology 2000; 141 : 3852-3861. 